\title{
PROSES PRODUKSI SUPERHEATER TUBE YOSHIMIN BOILER H-3500 TIPE CAP120 T/H
}

\author{
SUPERHEATER TUBE YOSHIMIN BOILER H-3500 PROCESS PRODUCTION \\ TYPE CAP120 T/H
}

\author{
Tri Hartutuk Ningsih ${ }^{1}$, Anggra Fiveriati ${ }^{2}$, Abdul Ghoni $^{3}$ \\ 1triningsih@unesa.ac.id \\ 2anggrafiveriati@poliwanggi.ac.id \\ 3abdulghoni@mhs.unesa.ac.id
}

\begin{abstract}
Abstrak - Jurnal ini menjelaskan proses produksi superheater tube yoshimin boiler H-3500 tipe CAP.120 T/H. Superheater tube merupakan sebuah komponen boiler subcritical yang berfungsi untuk memanaskan kembali uap saturated, pada tekanan kerja konstan, sehingga menjadi uap superheated. Teknologi superheater sudah digunakan sejak awal penggunaan mesin uap di sekitar awal abad 20. Tujuan utamanya adalah untuk meningkatkan energi panas yang terkandung di dalam uap, sehingga efisiensi termal mesin ikut meningkat. Hingga saat ini penggunaan superheater masih sangat populer, terutama pada boiler-boiler pipa-air besar pembangkit listrik tenaga uap. Proses produksi superheater tube yoshimin boiler $\mathrm{H}-3500$ tipe CAP.120 T/H di PT. Bromo Steel (PT. BOSTO) Indonesia melewati beberapa tahapan yaitu persiapan material, pembuatan mal, marking cutting, proses bending, proses fitting up, proses pengelasan, dan terakhir yaitu proses control product untuk menjamin kualitas pengerjaan.
\end{abstract}

Kata Kunci-Superheater Tube Yoshimin Boiler H-3500, Boiler Subcritical, Uap Saturated, Marking Cutting, Fitting Up.

The journal describes the production process superheater yoshimin boiler tube H-3500 type CAP.120 T/H .Superheater tube is a component that serves to heat boilers subcritical saturated steam back, constant work on pressure, so that it becomes superheated steam .Superheater technology has been used since the beginning of the use of a steam engine around the beginning of the 20th century. The main purpose is to increase the heat energy that is contained in steam, so as to increase significantly the thermal efficiency. Until now the use of superheater is still very popular, especially in large boilers water pipe steam power plant. Process of producing superheater yoshimin boiler tube H-3500 type CAP.120 T/H at PT. Bromo Steel (PT. BOSTO) Indonesia through several phases preparation; material preparation, making mal, marking cutting, bending process, the process fitting up, process welding, and the control process to ensure the quality of the product.

Key Words - Superheater Tube Yoshimin Boiler H-3500, Boiler Subcritical, Uap Saturated, Marking Cutting, Fitting Up.

\section{PEndahuluan}

Superheater adalah sebuah komponen boiler subcritical yang berfungsi untuk memanaskan kembali uap saturated, pada tekanan kerja konstan, sehingga menjadi uap superheated. Teknologi superheater sudah digunakan sejak awal penggunaan mesin uap di sekitar awal abad 20. Tujuan utamanya adalah untuk meningkatkan energi panas yang terkandung di dalam uap, sehingga efisiensi termal mesin ikut meningkat. Hingga saat ini penggunaan superheater masih sangat populer, terutama pada boiler-boiler pipa-air besar pembangkit listrik tenaga uap.

\section{KAJIAN PUSTAKA}

\section{A. Superheater Tube}

Secara sederhana boiler pipa api tersebut tersusun atas dua buah tanki air di sisi bawah dan atas. Kedua tanki tersebut terhubung dengan pipa-pipa air yang biasa kita kenal dengan raiser tube. Panas dari hasil pembakaran akan lebih dulu melewati raiser tube, dengan harapan air mencapai titik saturasinya dan berubah fase menjadi uap saturated.

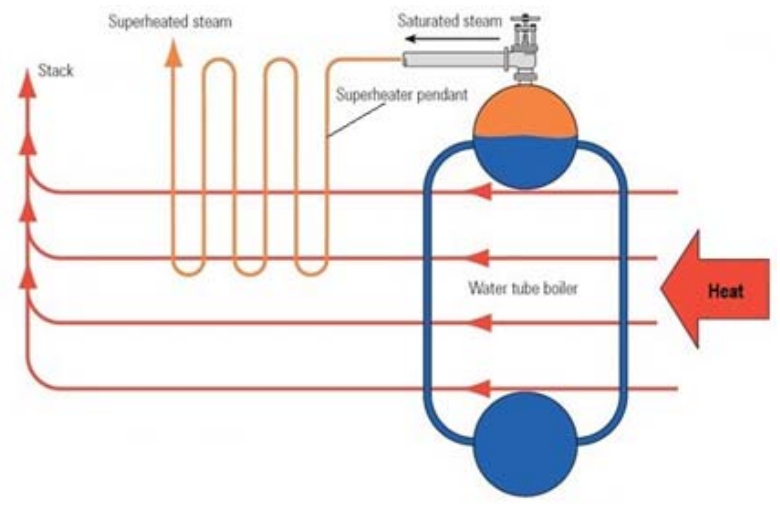

Gbr. 1 Superheater Tube

Sumber : Artikel Teknologi

Uap saturated masih bercampur dengan air sehingga dibutuhkan sebuah mekanisme untuk memisahkan uap saturated dengan air. Hal inilah yang menjadi fungsi dari tanki sisi atas. Tanki ini biasa kita kenal dengan nama upper generating drum. Air akan tetap tinggal di dalam upper generating drum dan akan tersirkulasi untuk dipanaskan kembali oleh raiser tube. Sedangkan uap saturated akan keluar dari upper generating drum dan menuju pipa-pipa 
superheater. Pipa-pipa yang kita kenal dengan superheater pendant ini akan menyerap panas secara konveksi dan radiasi dari gas buang pembakaran, hingga uap saturated dapat semakin mengering dan menjadi uap superheated. Uap superheated keluaran superheater akan memiliki kandungan energi panas yang lebih besar daripada uap saturated.

\section{B. Proses produksi Superheater Tube}

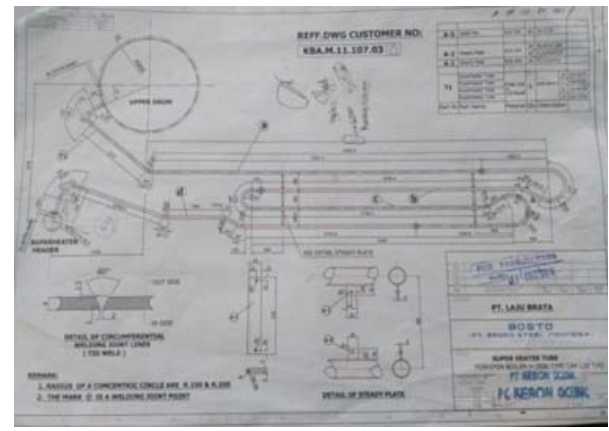

Gbr. 2 Rancangan Superheater Tube

Proses produksi superheater ini yaitu dengan cara membengkokkan lonjoran pipa membentuk sudut $r$ sesuai gambar dengan menggunakan mesin bending. Proses bending dibagi menjadi 4 pos yaitu, a, b, c, dan d. Setiap pos nantinya akan disambungkan dengan pengelasan GTAW. Pengelasan tidak boleh terjadi pada bengkokan/bending. Pipa yang digunakan sesuai standart untuk superheater yaitu, pipa STBA $22 \mathrm{~s}$ dengan diameter $50,8 \mathrm{~mm}$.

Sebelum melakukan proses bending, terlebih dahulu menghitung bentangan pipa. Rumus menghitung bentangan pipa adalah :

Bentangan $=2 \pi / 360 \times \mathrm{r} \times$ sudut

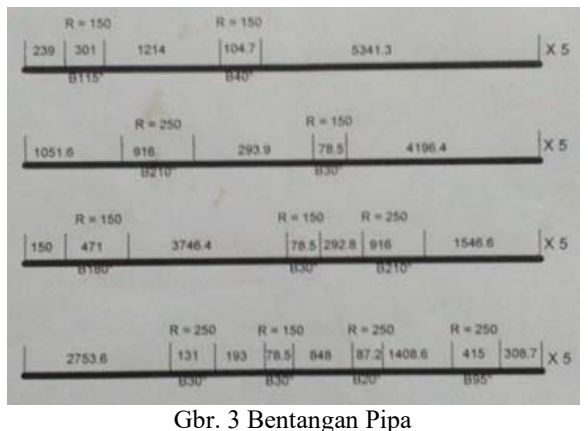

Setelah diketahui bentangan pipa, kemudian akan digambar ulang secara manual gambar superheater dengan skala 1:1 sebagai mal. Selanjutnya dilakukan pemotongan pipa sesuai kebutuhan pipa kemudian dilanjutkan dengan proses bending dengan menggunakan mesin bending.

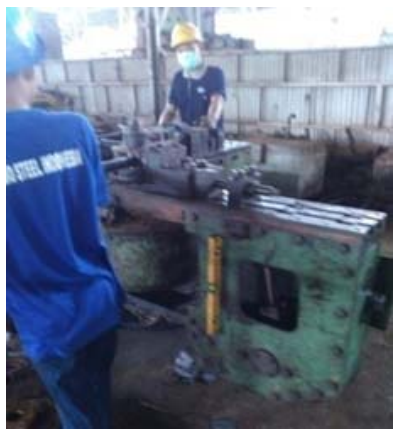

Gbr. 4 Proses Bending Pipa

(Sumber : PT. Bromo Steel Indonesia (BOSTO))

Gambar mal yang telah dibuat akan menjadi patokan untuk hasil bending. Hasil bending diletakkan diatas mal untuk mengecek ukuran sudut yang dikerjakan.

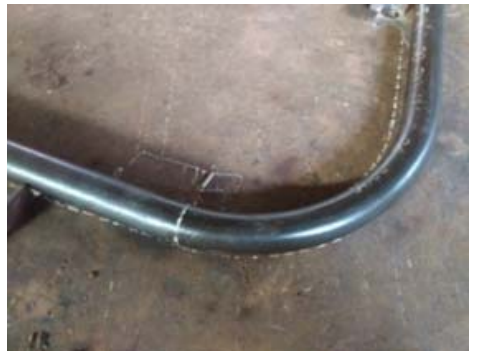

Gbr. 5 Mal Bending

Setelah semua pipa selesai melalui proses bending dengan ukuran yang tepat dilanjutkan dengan pembuatan kampuh las. Pembuatan kampuh las menggunakan gerinda untuk membentuk sudut kampuh sesuai gambar.

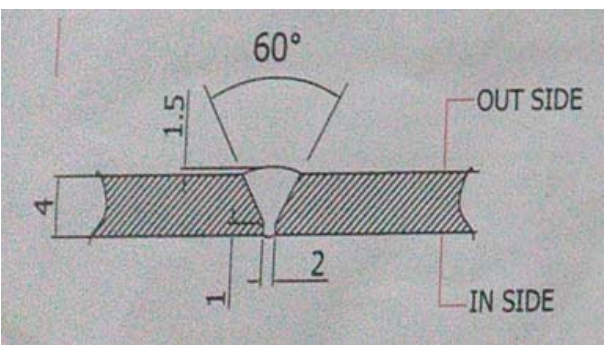

Gbr. 6 Rancangan Kampuh Las

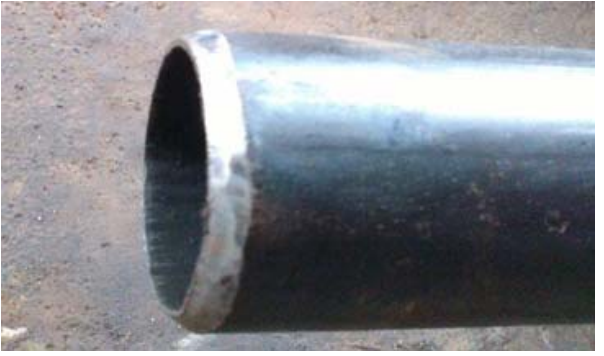

Gbr. 7 Kampuh Las

(Sumber : PT. Bromo Steel Indonesia (BOSTO)) 
Kemudian dilanjutkan proses fitt up yaitu pengelasan sementara dengan pengelasan di beberapa titik saja. Proses fitt up terlihat mudah namun sebenarnya sangat rumit karena membutuhkan ketelitian. Sambungan harus benar-benar lurus sesuai gambar karena mengingat fungsi superheater yang menjadi salah satu bagian vital pada boiler. Diperlukan bantuan penjepit untuk menjepit pipa agar tetap dalam posisinya dan kawat berdiameter $2 \mathrm{~mm}$ untuk menetapkan posisi kampuh. Selain itu, digunakan penggaris kecil untuk mengecek siku dari sambungan.

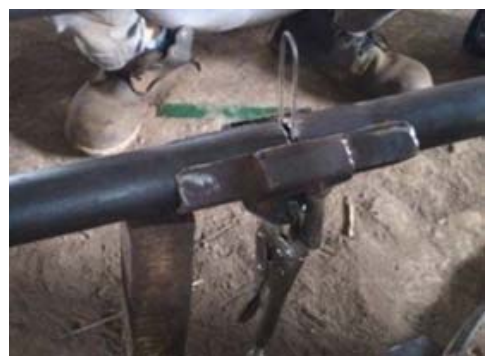

Gbr. 8 Persiapan Fitt Up

(Sumber : PT. Bromo Steel Indonesia (BOSTO))

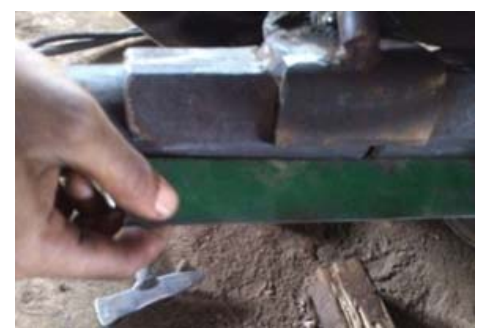

Gbr. 9 Proses Fitt Up

(Sumber : PT. Bromo Steel Indonesia (BOSTO))

Setelah pipa sudah pada posisi yang tepat, lakukan las di beberapa titik mengelilingi diameter dari pipa.

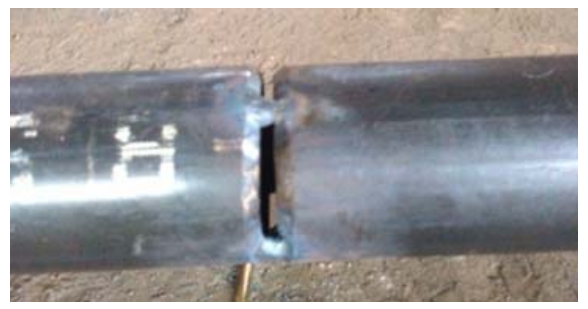

Gbr. 9 Fitt Up Pipa

(Sumber : PT. Bromo Steel Indonesia (BOSTO))

Selanjutnya pipa dilas permanen dengan menggunakan las GTAW dengan menggunakan kawat las TG-S50. Karena tebal pipa hanya 3,6mm dan tergolong kecil, pengelasan dilakukan bertahap dengan $2 x$ pengelasan. Jika pengelasan dilakukan secara langsung maka pipa akan mengalami cacat lengkung karena pipa tidak mampu menahan panas yang diterima selama proses pengelasan.

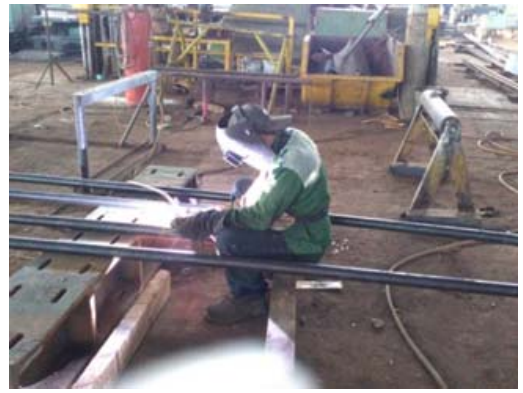

Gbr. 10 Pengelasan Pipa

(Sumber : PT. Bromo Steel Indonesia (BOSTO))

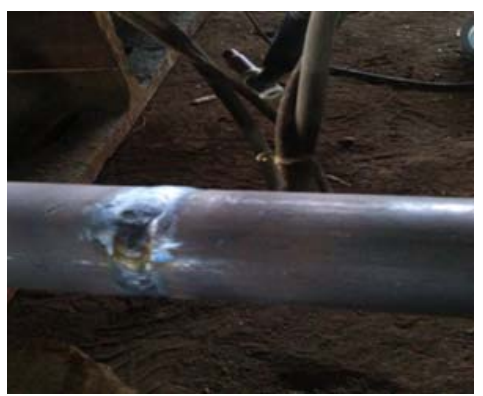

Gbr. 11 Pengelasan Pipa

(Sumber : PT. Bromo Steel Indonesia (BOSTO))

Selanjutnya persiapan pemasangan spacer/penyangga superheater. Spacer ini berfungsi untuk penyangga superheater agar tetap pada posisinya. Spacer menggunakan material SUS 304. Material spacer ditandandai kemudian dibor dan dipotong sesuai gambar. Proses pengeboran dilakukan sebelum pemotongan untuk mempermudah pengeboran mengingat ukurannya yang sangat kecil. Spacer ini nantinya akan dikuatkan dengan steady plate, yaitu plat yang disambungkan dengan spacer.

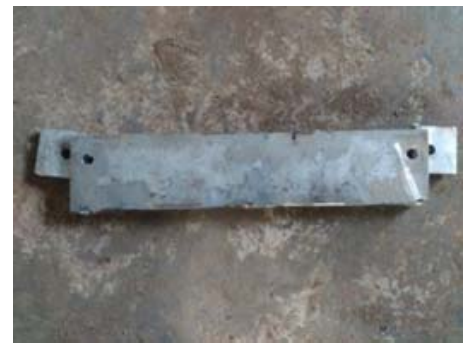

Gbr. 12 Spacer

Setelah spacer siap kemudian dilakukan pengelasan spacer terhadap pipa superheater. Spacer yang sudah tersambung dengan pipa, dihubungkan dengan steady plate untuk mengokohan posisi superheater. 


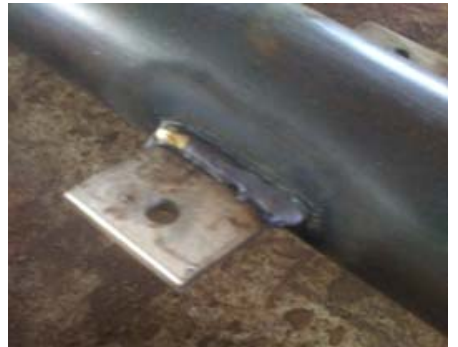

Gbr. 13 Pemasangan Spacer

(Sumber : PT. Bromo Steel Indonesia (BOSTO))

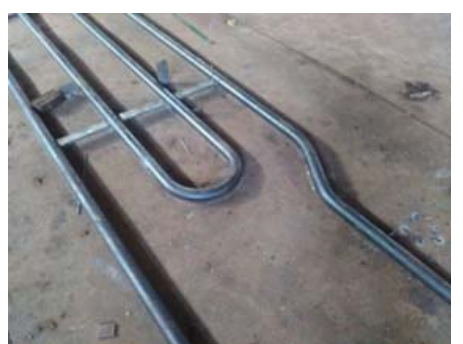

Gbr. 14 Pemasangan Spacer

(Sumber : PT. Bromo Steel Indonesia (BOSTO))

Proses pemasangan spacer merupakan tahap akhir dalam proses pembuatan superheater tube. Selanjutnya dilakukan pengujian hydrotest pada pipa untuk mengecek kebocoran. Sesuai permintaan dan kebutuhan pemesan, hydrotest harus dilakukan dengan melakukan penekanan pipa dengan media air bertekanan $36 \mathrm{Kg} / \mathrm{cm}^{2}$ selama 30 menit.

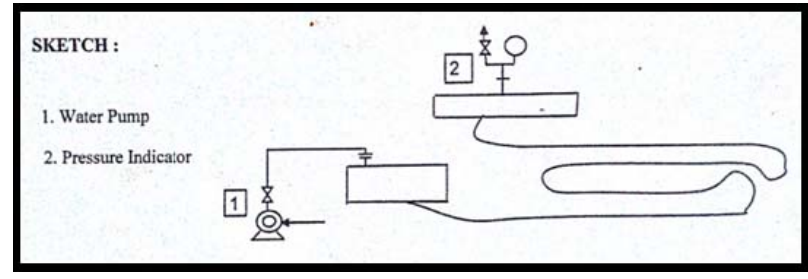

Gbr. 15 Skema Proses Hydrotest

(Sumber : PT. Bromo Steel Indonesia (BOSTO))

Sebelum melakukan tes, dilakukan beberapa persiapan yaitu membuat sekaligus memasang pipa bantuan untuk pemasangan alat uji pada pipa. Alat uji berupa water pump yang dipasang pada ujung masukan air dan pressure indicator dipasang pada ujung sisi pipa yang lain untuk mengontrol tekanan yang diterima pipa.
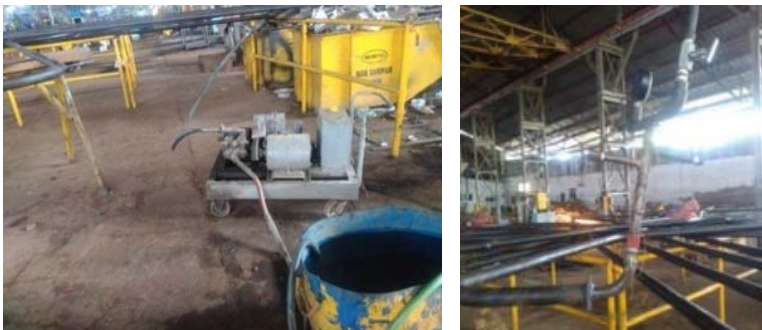

Gbr. 15 Proses Hydrotest

Pada kegiaatan ini tes dilaksanakan pada 9 Januari 2019, dimulai pada pukul 10:50. Tes dilakukan bertahap, pada pukul 10:52 sampai 10:57 yaitu selama 5 menit dilakukan penekanan sebesar $20 \mathrm{Kg} / \mathrm{cm}^{2}$ dan pipa tidak menunjukkan tanda kebocoran. Selanjutnya pada pukul 11.00 sampai 11.30 yaitu selama 30 menit dilakukan penekanan sebesar 36 $\mathrm{Kg} / \mathrm{cm}^{2}$ dan tidak menunjukkan tanda kebocoran ini menandakan bahwa pipa superheater telah lolos uji hydrotest.

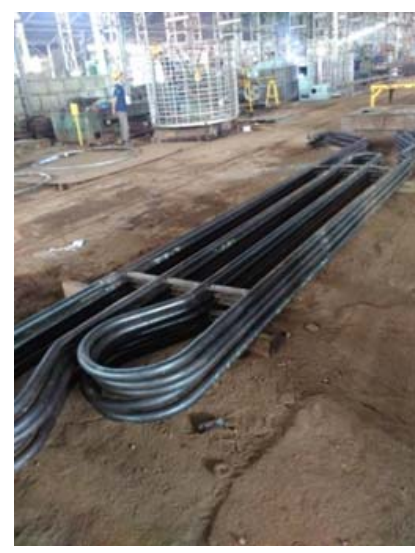

Gbr. 9 Produk Superheater Tube

Dari tahapan proses produksi diatas dapat diambil kesimpulan bahwa pembuatan komponen superheater tube di PT. Bromo Steel Indonesia melewati beberapa tahapan yaitu : persiapan material, pembuatan mal, marking cuting, proses bending, proses fitting up, proses pengelasan, dan terakhir yaitu proses control product untuk menjamin kualitas pengerjaan.

\section{REFERENSI}

[1] Aprilian, Dicky. 2018. Proses Rolling Reflux Drum (Super Grade). Jember: PPs Universitas Jember

[2] Djarwanto. 1982. Pengertian Rolling, (Online), (http://teknikmesinmanu faktur.blogspot.co.id/2015/06/rolling.html).

[3] Duskiardi. 1982. Makalah Pengerolan Logam, (Online), (http:// www.acade mia.edu/23849510/Makalah_Rolling.html).

[4] Suyono, Joko. 2016. Proses dan Jenis Pengelasan. Pasuruan: PT. Bromo Steel Indonesia.

[5] Teknologi, Artikel. Prinsip Kerja Superheater, (Online), (http://artikelteknologi.com/prinsip-kerja-superheater/)

[6] Teknologi, Artikel. Steam Drum Pada Boiler Pipa Air, (Online), (http:// artikel-teknologi.com/steam-drum-pada-boiler-pipa-air/)

[7] Tim Penyusun. (2014). "Buku Panduan Praktik Industri (PI)/Praktik Kerja Lapangan (PKL) Fakultas Teknik Unesa”. Surabaya: Unesa Press

[8] PT BOSTO. 2014. Denah Perusahaan, (Online), (http://www. Bromosteel indonesia-ptbosto.com/p/blog page_5261.html). 
[9] PT BOSTO. 2014. Gambaran Perusahaan, (Online), (http://www. Bromo steelindonesia-ptbosto.com $/ \mathrm{p} / \mathrm{sejarah}$-perusahaanperusahaandidi rikan .html).

[10] PT BOSTO. 2014. Profil Bromo Steel Indonesia PT, (Online), (http://www.bromosteelindonesia-ptbosto.com/p/profil-bromo-steelindonesia-pt-bosto-pt.html) 